\title{
EVALUATION OF WARM-MIX ASPHALT MIXTURES USING LEADCAP ADDITIVE
}

\author{
Kim, Yongjoo, Ph. D, Senior Researcher, Dept. of Highway Division, Korea Institute of Construction \\ Technology, 1190, Simindae-Ro, Ilsanseo-Gu, Goyang-Si, Gyeonggi-Do, Republic of Korea, E-mail: \\ yongjook@kict.re.kr \\ Lee, Jaejun, Ph. D, Senior Researcher, Republic of Korea. \\ Baek, Cheolmin, Ph. D, Senior Researcher, Republic of Korea. \\ Kwon, Sooahn, Ph. D, Senior Researcher, Republic of Korea \\ Suh, Youngchan, Ph. D, Professor, Department of Transportation Engineering, Hanyang University, Republic of \\ Korea. \\ Son, Jongcheol, Ph. D, Director, Road Planning \& Construction Division, Ministry of Land, Transport and \\ Maritime Affairs, Gyeonggi-Do, Republic of Korea.
}

doi: 10.2478/ijpeat-2013-0004

\section{ABSTRACT}

Warm-mix asphalt (WMA) is an emerging technology that can allow asphalt to flow at a lower temperature for mixing, placing and compaction. This technology can reduce energy consumption during asphalt production and reduce carbon dioxide emission and asphalt oxidation as well as extend asphalt paving season and delivery distance under enhanced working environment at the field. In Korea, an innovative wax-based WMA additive, which is named low energy and low carbon-dioxide asphalt pavement (LEADCAP), was developed to reduce mixing and paving temperatures applied in asphalt paving process. Since the first field trial project using the LEADCAP WMA technology in 2008, many LEADCAP WMA field trial projects have successfully been completed in Europe, United States and Asia. In this paper, the LEADCAP WMA mixtures along with the control hot-mix asphalt (HMA) mixtures were evaluated with respect to their crack resistance and rutting resistance based on the dynamic modulus test and full-scale accelerated pavement test (FSAPT). With the limited data carried out, it is concluded that LEADCAP additive can be effectively applied to WMA mixtures and LEADCAP WMA pavement is expected to perform comparable to HMA pavement.

\section{INTRODUCTION}

In 1997, the efforts to lower production temperature of hot-mix asphalt (HMA) by between 25 and $55^{\circ} \mathrm{C}$ were introduced at the German Bitumen Forum (D'angelo et al. 2008). It was called warm-mix asphalt (WMA) technology that can allow asphalt to flow at a lower temperature for mixing, placing and compaction. A number of WMA technologies have been developed to allow asphalt mixture to be produced and compacted at a significantly lower temperature. The WMA technology has become popular in recent years because of the economical and environmental advantages in the world (Anderson et al, 2008). Brian and Graham (2008) reported an investigation of WMA technologies from Europe in 2002 resulting in the first WMA public demonstration project in the United States in 2004. NAPA (2008) published a WMA related documentation that included mix design and field trial data. A number of WMA projects and the total WMA quantities including trials and demonstration 
projects significantly increased in a short period of time span of 5 years from 2005 to 2010 . Part of these technologies is based on the use of additives to modify the viscosity or workability of the asphalt binder incorporated in the asphalt mixture. Korea Institute of Construction Technology (KICT) and Kumho Petrochemical Co., LTD. have jointly invented an innovative WMA additive which is named low energy and low carbon-dioxide asphalt pavement (LEADCAP) in Korea. The main objectives of this study are to measure the emissions and fuel consumption during the production of WMA LEADCAP mixture and conventional HMA mixture in the plant and to evaluate crack and rutting resistances of LEADCAP WMA mixture along with the conventional HMA mixture based on the dynamic modulus test and full-scale accelerated pavement test (FSAPT).

\section{CHARACTERISTICS OF LEADCAP WMA ADDITIVE}

A number of WMA technologies are commercialized and classified as 1) organic, 2) foaming and chemical. With organic additives, the viscosity of asphalt is reduced at the temperature above the melting point in order to produce asphalt mixtures at lower temperatures. As shown in Figure 1, the LEADCAP is classified as an organic WMA additive, which is a wax-based composition including crystal controller to adjust crystalline degree of wax material at the low temperature and adhesion promoter to enhance adhesion between asphalt and aggregate.
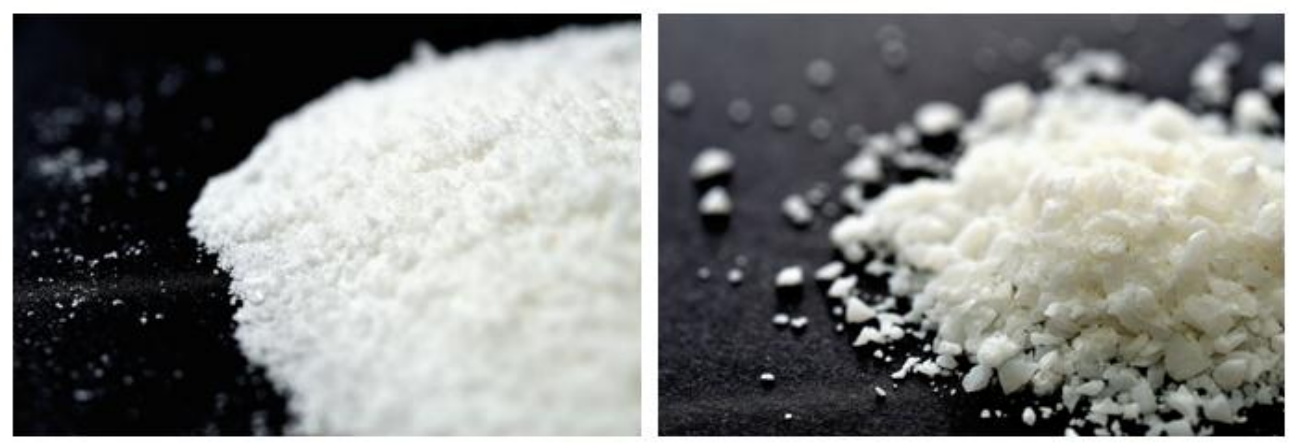

Figure 1. LEADCAP WMA Additive

The LEADCAP additive, that has melting points below a normal HMA production temperature, can be added the asphalt mixture (plant-mixed type) or asphalt (pre-mixed type) allowing for the production and placement of the mixture at a $30^{\circ} \mathrm{C}$ below temperature of conventional HMA mixture. Typically, LEADCAP additive is added at the rate of $1.5 \sim 2.0 \%$ by weight of asphalt.

\section{APPLICATIONS OF LEADCAP WMA TECHNOLOGY IN THE FIELD}

To investigate workability and compactability of LEADCAP WMA mixtures in the field, as shown in Figure 2, the first LEADCAP WMA field trial section was constructed on Sinryeong-Gono Interstate Highway in Korea on October 13, 2008. Since then, nine LEADCAP WMA field trials were successfully completed on the Interstate Highway (7 sections) and expressway (2 sections) from 2008 to 2010 in Korea. Based on the field measurements of air voids, it was found that the field air voids of LEADCAP WMA and 
HMA test sections were not significantly different. It indicates that LEADCAP additive would be effective in producing and compacting WMA mixtures that are comparable to HMA mixtures. It was also found that there is no significant distress in both the WMA and the HMA field trial sections during the first and second year in service life.
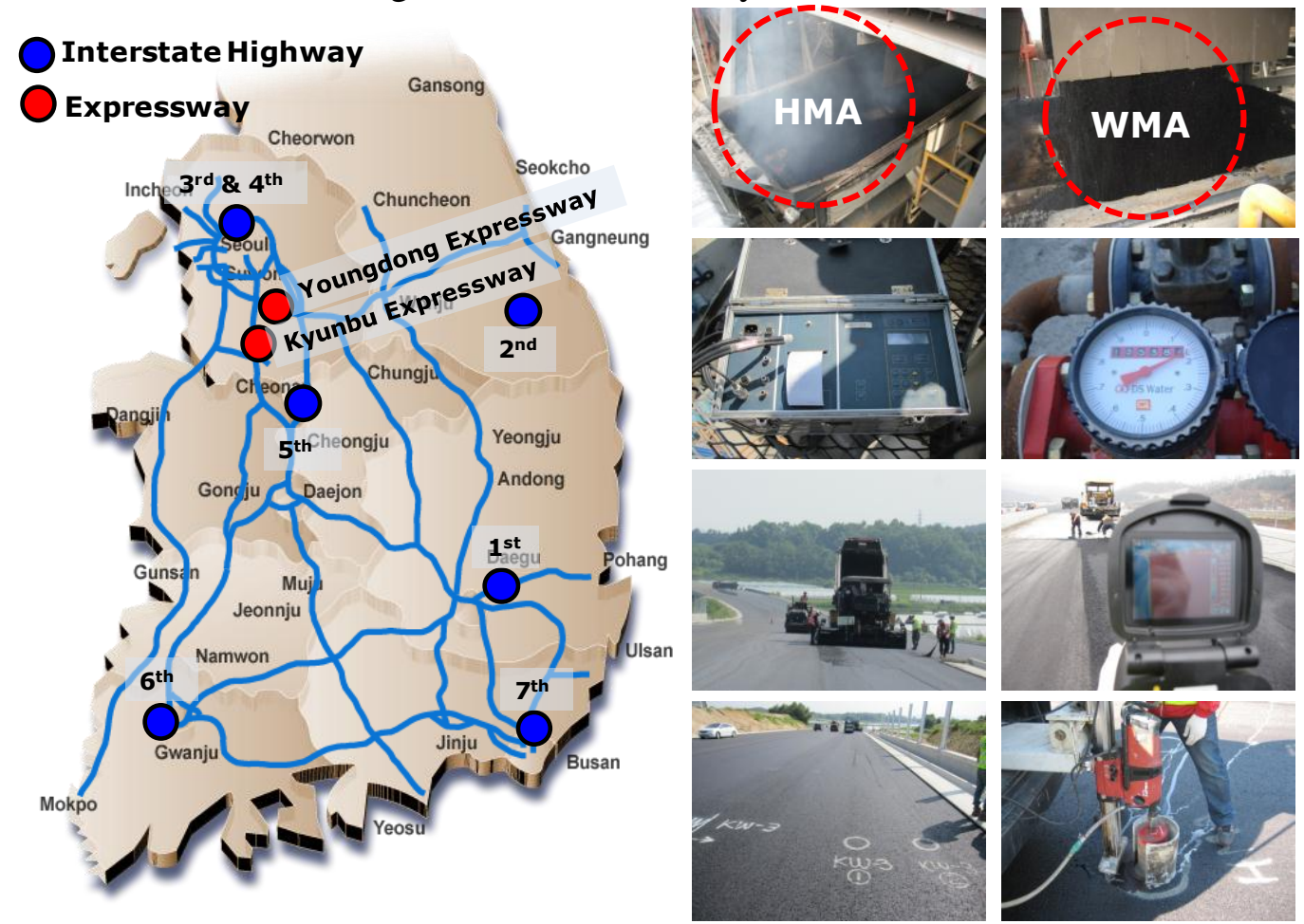

Figure 2. LEADCAP WMA Field Trials in Korea

\section{Measurement of Fuel Consumption and $\mathrm{CO}_{2}$}

During the production of LEADCAP WMA mixtures at $130^{\circ} \mathrm{C}$ and conventional HMA mixtures at $160^{\circ} \mathrm{C}$ in the plant, the use of bunker $\mathrm{C}$ oil and carbon dioxide $\left(\mathrm{CO}_{2}\right)$ were measured. Figure 3 shows fuel consumption and $\mathrm{CO}_{2}$ data collected from the second LEADCAP WMA field trial. As shown in Figure 2, the decreased production temperatures lead to energy savings of $32 \%$, which results in $32 \%$ reduction of $\mathrm{CO}_{2}$. It indicates that the LEADCAP additive would be effective to reduce energy use and the emission during the production of WMA mixtures in the plant.
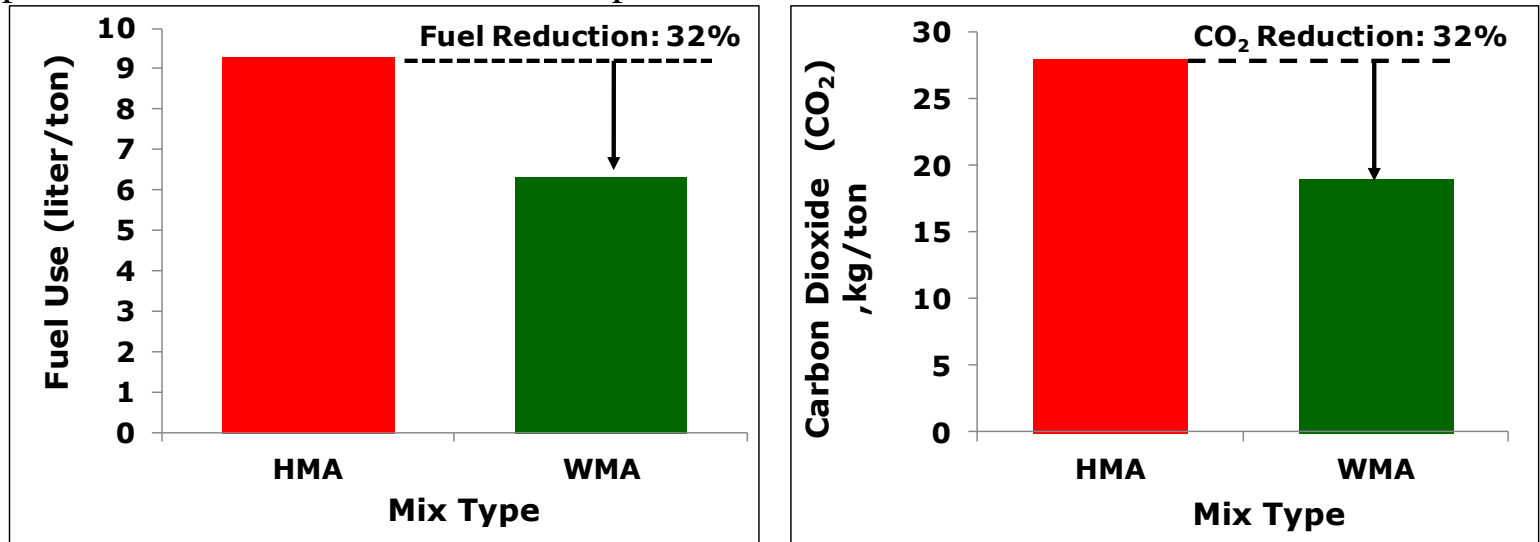

Figure 3. Reductions of Fuel Consumption (left) and $\mathrm{CO}_{2}$ (right) 


\section{Application of LEADCAPAdditive to Various Asphalt Mixtures}

To find out the use of the LEADCAP additive to various asphalt mixtures through the field trials, as shown in Figure 4, the LEADCAP additive was used in dense-graded asphalt mixture in Portugal and Italy, SBS modified porous asphalt mixture in Japan, SBS modified SMA asphalt mixture in China and dense-graded asphalt mixture with RAP materials in United States from 2010 to 2011. The LEADCAP additive is successfully applied for various asphalt mixtures. It can be postulated that the LEADCAP additive can be used in all of asphalt mixtures without any problems such as coating, segregation, mixing and compaction.

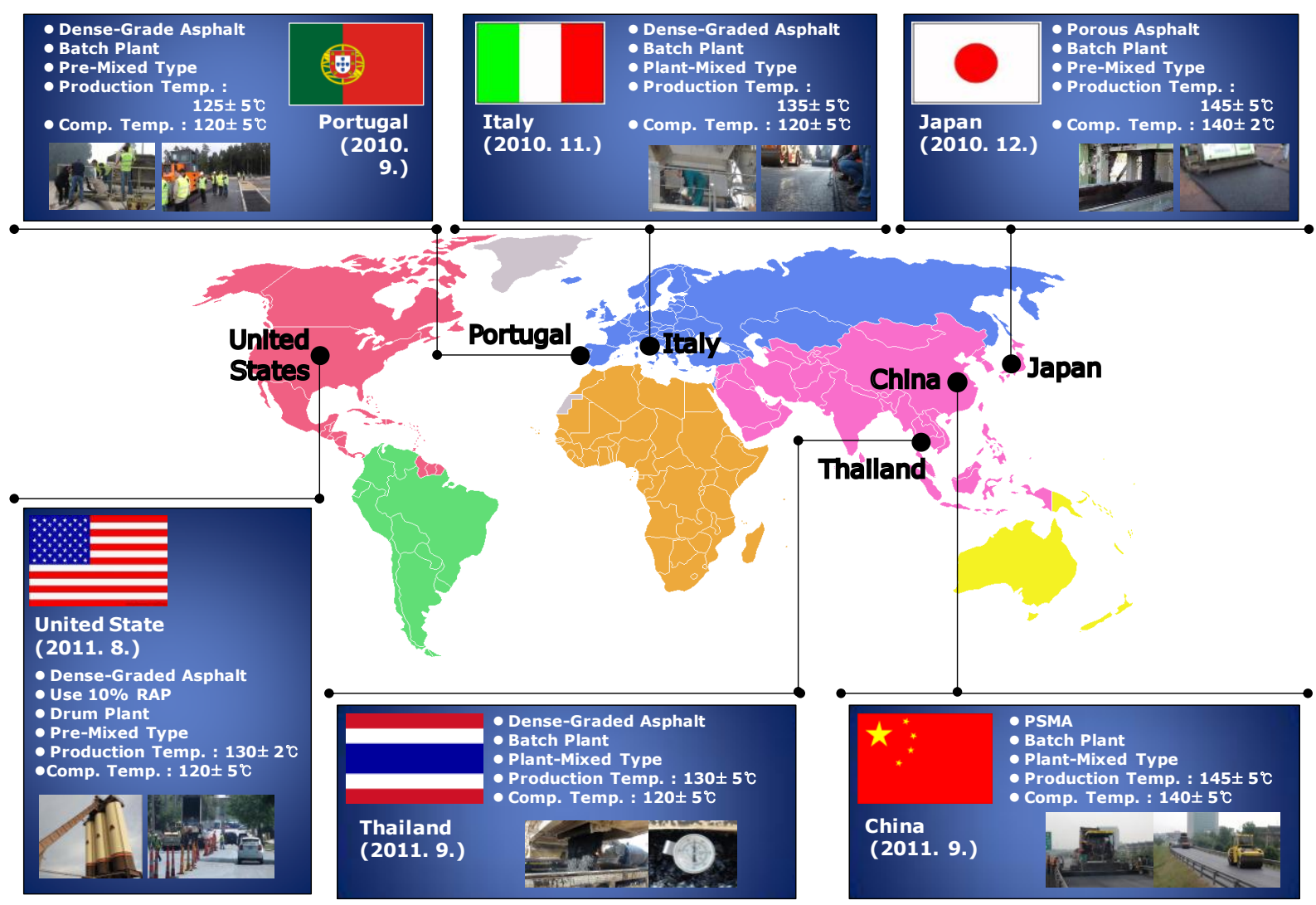

Figure 4. Field Trials of Various WMA Mixtures using LEADCAP Additive

\section{DYNAMIC MODULUS TEST}

The dynamic modulus test was performed in stress-controlled uniaxial compression mode, generally following the protocol given in AASHTO TP62-03 (AASHTO 2003). The test was performed at frequencies of $25,10,5,1,0.5,0.1,0.05$, and $0.01 \mathrm{~Hz}$ at four different testing temperatures of $-10,10,35$, and $54^{\circ} \mathrm{C}$. The loading level was determined by a trial and error process so that the resulting strain amplitudes were between 50 and 70 microstrains. Testing specimens were compacted by the Servopac Superpave gyratory compactor, manufactured by IPC Global of Australia, to dimensions of $178 \mathrm{~mm}$ in height and $150 \mathrm{~mm}$ in diameter. To obtain specimens of uniform quality for testing, these specimens were cored and cut to a height of $150 \mathrm{~mm}$ and a diameter of $100 \mathrm{~mm}$. The air voids of the cored specimens for dynamic modulus test are between 5.0\% and 6.0\%. MTS 810 machine was used and axial 
deformations of specimen were measured during testing at $120^{\circ}$ intervals over the middle 85 $\mathrm{mm}$ of the specimen using MTS extensometers.

\section{Test Results and Analysis}

Figure 5 presents the dynamic modulus test results of the LEADCAP WMA and conventional HMA mixtures. A reference temperature of $5^{\circ} \mathrm{C}$ was used to create sigmoidal dynamic modulus mastercurves of each mixture. The dynamic modulus mastercurves in semi-log and $\log$-log scales in Figure 5 (a) and (b) can be used to evaluate the linear viscoelastic characteristics of mixtures in low temperature range and high temperature range, respectively. It is observed that, in general, the LEADCAP WMA mixture and the HMA mixture exhibit very similar linear viscoelastic behavior over all of the frequency ranges. The mixture exhibiting low stiffness at high reduced frequencies and high stiffness at low reduced frequencies is generally expected to have a good resistance to both cracking and rutting. With respect to the phase angle mastercurves presented in Figure 5 (c), LEADCAP WMA mixture shows less elastic behavior (high phase angle values) at low and intermediate temperatures but most elasticity at high temperature. Based on the dynamic modulus test results, it is expected that the fatigue and rutting performance of the LEADCAP WMA mixture and the HMA mixture would be comparable. In order to evaluate the performance of two mixtures more directly, the full-scale accelerated pavement test was conducted and the details are shown in the next section.

\section{FULL-SCALE ACCELERATED PAVEMENT TEST}

The full-scale accelerated pavement testing (FSAPT) is widely used in the world to apply a prototype wheel loading with appropriate legal load limit to a structural pavement system to deter mine pavement response and performance under accumulated damage in a compressed time period. FSAPTR can be evaluated pavement performance as function of various variable factors such as materials and thickness. For this study, FSAPT was adopted to compare HMA mixture to LEADCAP WMA mixture. To evaluate rutting resistance of LEADCAP WMA mixture along with a conventional HMA mixture, as shown in Figure 6, full-scale accelerated pavement test (APT) was conducted on the test bed at indoor facility. To build the LEADCAP WMA test bed along with a HMA test bed, as shown in Figure 6, WMA mixture using 2.0\% LEADCAP of asphalt weight was produced at $130 \pm 5^{\circ} \mathrm{C}$ and compacted at $110^{\circ} \mathrm{C} \pm 5^{\circ} \mathrm{C}$ while HMA mixture was produced at $160 \pm 5^{\circ} \mathrm{C}$ and compacted at $130^{\circ} \mathrm{C} \pm 5^{\circ} \mathrm{C}$. 

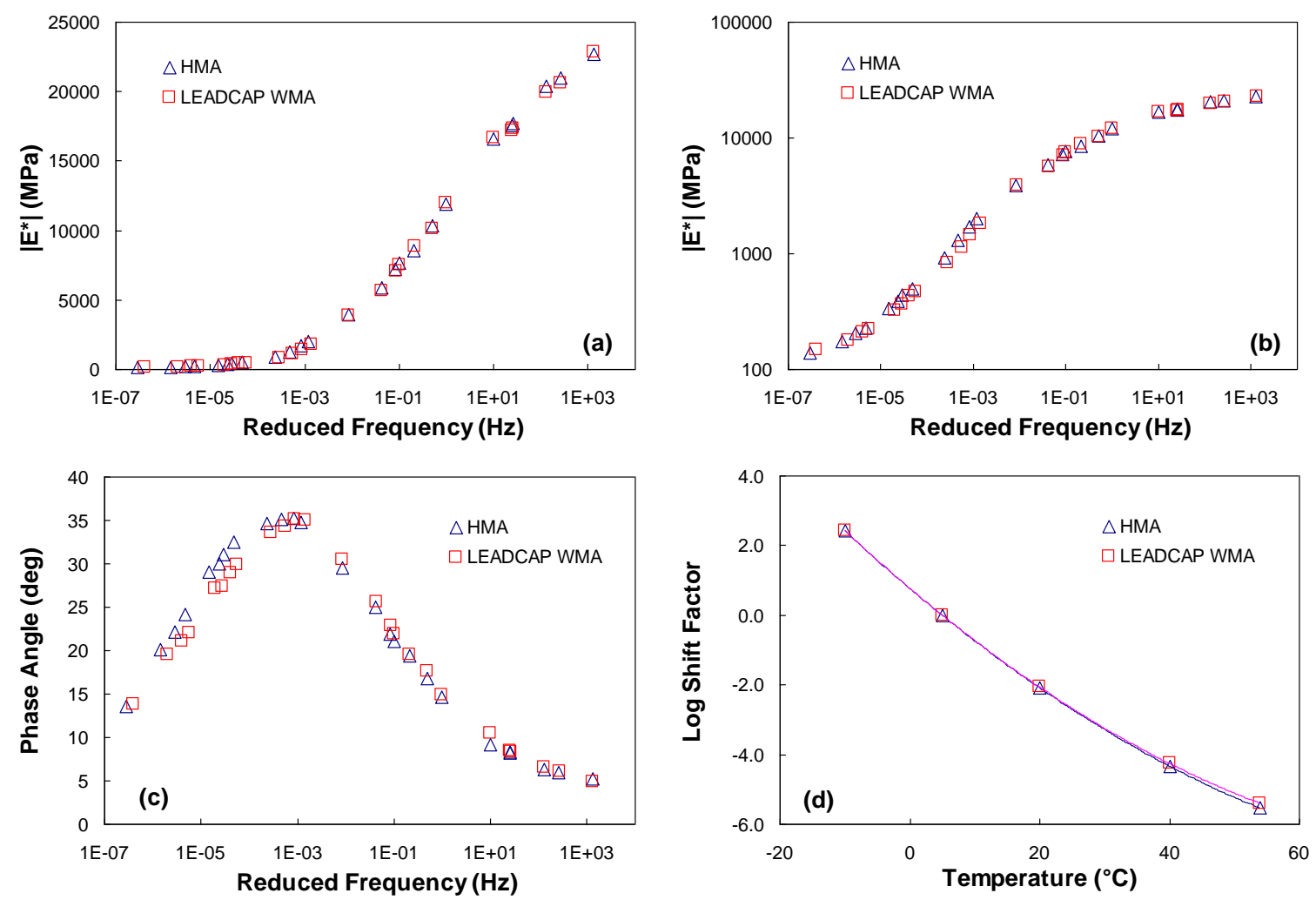

Figure 5. Dynamic modulus test results of LEADCAP WMA and HMA mixtures: (a) $\left|E^{*}\right|$ mastercurves in semi-log space, (b) $\left|\mathrm{E}^{*}\right|$ mastercurves in log-log space, (c) phase angle mastercurves, and (d) shift factor function.
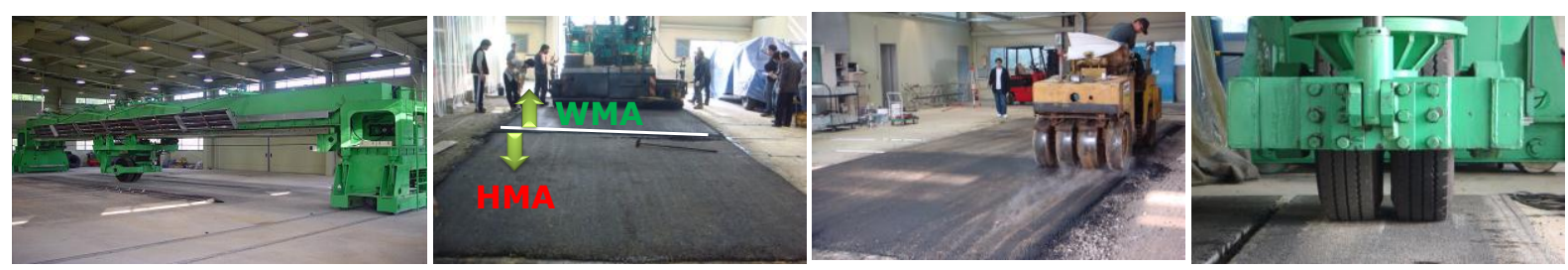

Figure 6. Test Beds for Full-Scale Accelerated Pavement Test

\section{TEST RESULTS AND ANALYSIS}

Figure 7 and Figure 8 are described the FSAPT results between the LEADCAP WMA and the HMA mixtures. Figure 7 shows plot of the changed rut depth as function of loading cycles. As increased the loading cycle, the rut depth of both test beds is increased with similar trend. After given 56,400 loading cycle, the final rut depth of HMA test bed is slightly larger than that of the LEADCAP WMA test bed. It indicates that the LEADCAP WMA mixture is good for solving rutting distress of pavement. Figure 8 show the surface condition of measured rut depth place. 


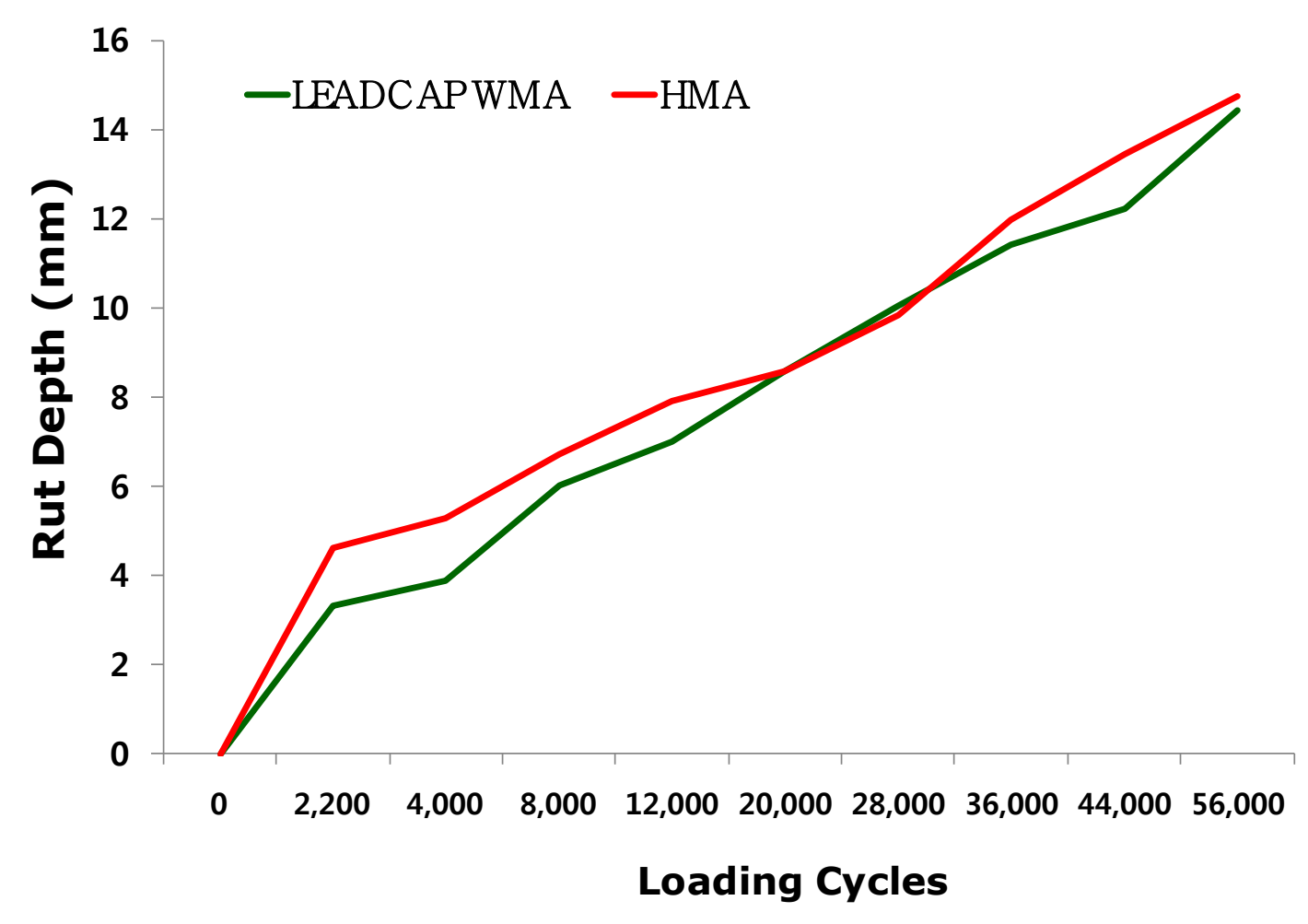

Figure 7. Comparisons of Rut Depths between LEADCAP WMA and HMA Sections
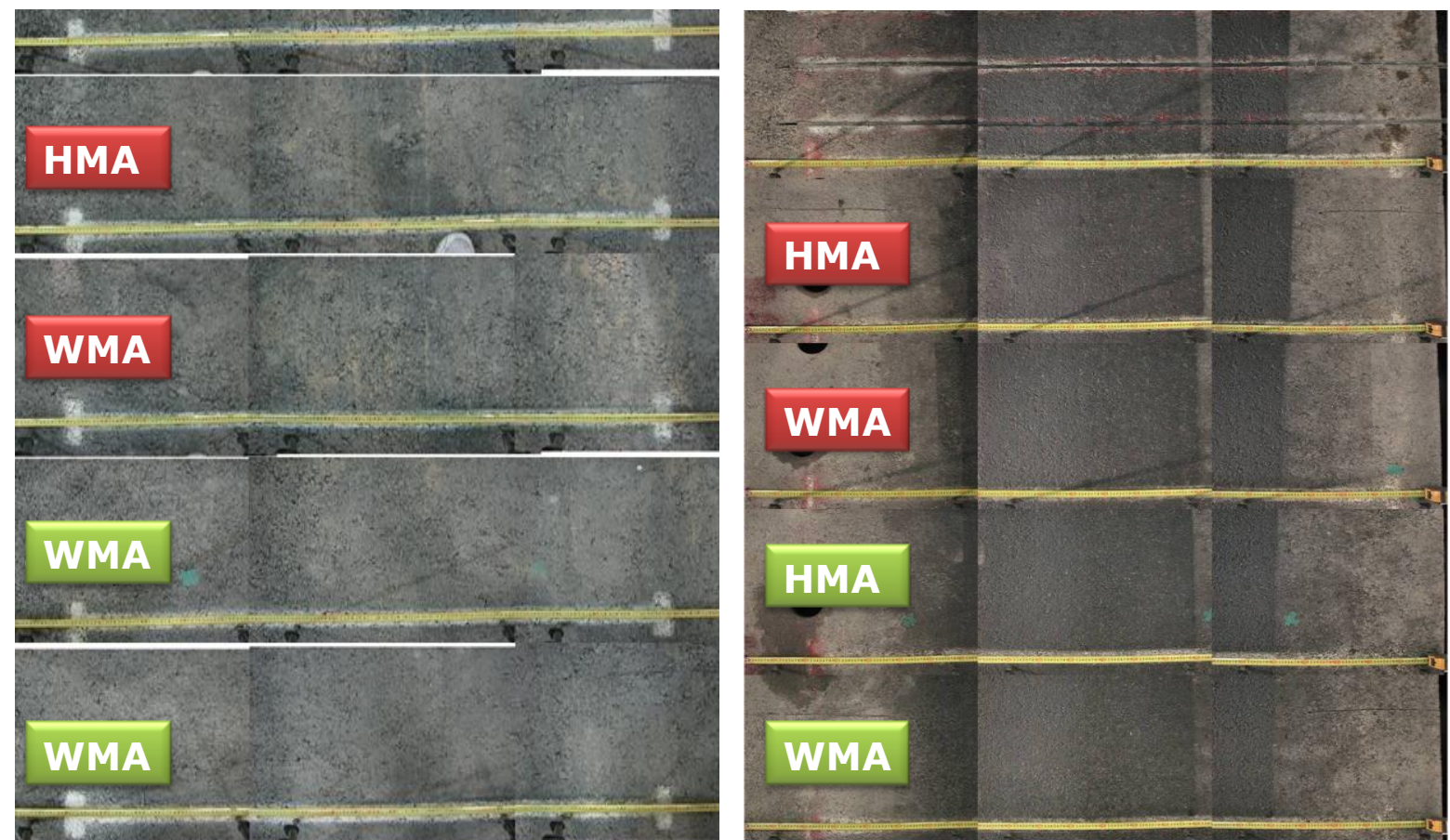

Figure 8. Surface Observations of LEADCAP WMA and HMA Sections 


\section{SUMMARY AND CONCLUSIONS}

A number of warm-mix asphalt (WMA) technology has been developed and successfully implemented in the world. Since WMA is mixed and placed at a lower temperature, the amount of green house gas emission from the asphalt plant is reduced while conserving the energy. Low energy and low carbon-dioxide asphalt pavement (LEADCAP), which is an organic WMA additive was developed in Korea. Several WMA field trial sections using LEADCAP additive were successfully constructed in Korea, Japan, China, United States, Portugal, and Italy. Given the limited field trials of the LEADCAP WMA pavement, it is concluded that the LEADCAP WMA pavement achieved a comparable air void as the HMA pavement at a significantly lower temperature. It indicates that the LEADCAP additive is effective in producing and compacting WMA mixtures that are comparable to the HMA mixtures. The energy savings and the air quality improvements by the LEADCAP WMA mixture were observed but long-term performance and durability of LEADCAP WMA pavement should be researched further. Based on the dynamic modulus test and FSAPT results, it is found that, in general, the LEADCAP WMA and the HMA mixtures exhibit very similar linear viscoelastic behavior over all of the frequency ranges. The mixture exhibiting low stiffness at high reduced frequencies and high stiffness at low reduced frequencies is generally expected to have a good resistance to both cracking and rutting. Total rut depth of HMA test bed is slightly higher than that of the LEADCAP WMA test bed. These results indicate that the LEADCAP WMA mixture is similar (or superior) to the HMA mixtures in crack and rutting resistances.

\section{REFERENCES}

American Association of State Highway and Transportation Officials. "AASHTO TP-62 Standard Method of Test for Determining Dynamic Modulus of Hot-Mix Asphalt Concrete Mixtures." AASHTO, Washington, D.C. (2003).

D’Angelo, J., Harm, E., Bartoszek, J., Baumgardner, G., Corrigan, M., Cowsert, J., Harman, T., Jamshidi, M., Jones, W., Newcomb, D., Prowell, B., Sines, R., and Yeaton, B. (2008) Warm-Mix Asphalt: European Practice, Office of International Programs, Federal Highway Administration. Washington. D.C.

Anderson, R. M., Baumgardner, G., May, R. and Reinke, G. (2008) NCHRP 9-47:

Engineering Properties, Emissions, and Field Performance of Warm Mix Asphalt Technologies, Interim Report, National Cooperation Highway Research Program, Washington D.C.

Brian D. P. and Graham C.H. (2008) Warm-Mix Asphalt: Best Practices, National Asphalt Pavement Association, Information Series 125, Lanham, MD.

NAPA (2008) Warm-Mix Asphalt: Contractors" Experience, National Asphalt Pavement Association, Information Series 134, Lanham, MD. 